\title{
EL COMBATE INDIVIDUAL EN LOS LIBROS DE CABALLERÍA A LA LUZ DE SUS MOTIVOS
}

\author{
ANA CARMEN BUENO SERRANO²
}

Universidad de Zaragoza

\begin{abstract}
Resumen
Este trabajo propone un análisis de la función de los combates individuales en los libros de caballerías con unos pocos ejemplos al hilo del discurso que demuestren la contribución que desde la perspectiva de estudio de las constantes de contenido, que se han llamado motivos, puede hacerse a desentrañar la compleja, y a veces alambicada, poética de lo caballeresco. El rastreo de los materiales permite concluir que se selecciona del combate judicial aquello que mejor se amolda a los intereses de la prosa y que, sin que sirva de precedente, hay una correspondencia perfecta entre modelos contemporáneos, motivos folclóricos y motivos caballerescos.
\end{abstract}

Palabras clave: libros de caballerías, combates judiciales, folclore, motivos, hora de Cisneros.

\begin{abstract}
This article proposes an analysis of the function of the combat judiciaire in the Romances of Chivalry with some examples that show the contribution that from the perspective of study of the constants of content or Motifs, can do to study the complex knightly poetic. The track of the materials allows to conclude that it selects of the combat judicial that better adapts to the interests of the prose and that there is a perfect correspondence between contemporary models, folklore motifs and knightly motifs.
\end{abstract}

Key words: Romances of Chivalry, Combat judiciaire, Folklore, Motifs, hora de Cisneros.

\section{INTRODUCCIÓN}

En los libros de caballerías castellanos el enfrentamiento individual llega a ser la expresión material más acabada del ethos caballeresco; el resultado de este combate imaginario (Riquer y Vargas Llosa, 1972) tiene consecuencias legales, políticas, económicas y literarias ya que crea la ilusión de que el caballero es una fuerza legítima

\footnotetext{
${ }^{1}$ Este trabajo forma parte del proyecto del grupo Clarisel, reconocido por la DGA y dirigido por la Dra. María Jesús Lacarra. Cada una de las afirmaciones de este artículo tiene abundante y precisa bibliografía que, por razones de espacio, no menciono pormenorizadamente. Para ello remito a la Bibliografía de los libros de caballerías castellanos de Eisenberg y Marín Pina y, para referencias más recientes, a la Base de datos bibliográfica sobre literatura caballeresca "Clarisel" (http://clarisel.unizar.es), dirigida y coordinada desde la Universidad de Zaragoza por el Dr. Juan Manuel Cacho Blecua.

${ }^{2}$ Universidad de Zaragoza. Correo: anacarmen.bueno@yahoo.es. Recibido 28-12-2010. Aceptado: 31-012011.
} 
para administrar justicia y zanjar limpiamente disputas públicas y privadas. Esta exaltación de la actividad heroica hace que el personaje masculino se sienta un ser excepcional, dotado por nacimiento de un empuje y un código ético conformes a su superioridad física y moral. Por ello, al caballero se le atribuye, entre otras ventajas, la prerrogativa de vengar la agresión que sufre el débil o el menesteroso, conciliando en el mismo gesto este afán vindicatorio con su necesidad natural de gloria y lucimiento. Además, el triunfo armado en las primeras etapas de su cursus honorum augura un excepcional éxito en el campo de batalla, en la línea del héroe épico.

Los episodios prioritariamente bélicos, individuales o colectivos, sirven desde antes de la difusión de los libros de caballerías castellanos cuyas primeras ediciones conservadas se publican entre 1508 y 1516, es decir, durante la regencia del cardenal Cisneros (Amadís de Gaula, Sergas de Esplandián, Florisando, Palmerín de Olivia, Primaleón, Lisuarte de Grecia y Floriseo), para generar aventuras o resolver conflictos anteriores a la llegada del caballero, que laborat gratis et amore por el prójimo, en ocasiones sin más prueba de creencia que su palabra. Su intervención, sobre la que se centra la secuencia, es bien acogida por la confianza ciega de los injuriados en su buena fe. En ocasiones, el germen de la aventura estará, precisamente, en un comportamiento anticaballeresco como incumplimiento de la bona fides supuesta.

Los combates individuales en los libros de caballerías de la hora de Cisneros (Pérez, 1995) presentan referencias históricas y unas constantes que identifican el género y permiten su reconocimiento. Esta afinidad también se logra con un alto grado de "estereotipación" en todos los niveles del discurso. No obstante, es insuficiente explicar sus fórmulas y repeticiones de contenido como recursos de identificación de un género porque ahora son, también, parte importante de una "poética múltiple" (Cacho Blecua, 2005), que se construye a partir de variaciones de materiales preexistentes.

Los libros de caballerías no son literatura folclórica, si bien comparten ciertas constantes con un modelo folclórico que acaba novelizado en los moldes de la prosa. Por ello, acudir al folclore y, más concretamente, al catálogo de motivos folclóricos de Stith Thompson, permite explicar muchos episodios y enriquecer sus significados con nuevas interpretaciones y valiosas connotaciones.

Por otro lado, entendiendo, como he hecho siempre, el motivo como unidad recurrente de contenido (Cacho Blecua, 2002), propongo, a continuación y en paralelo al índice de Thompson, una segmentación del discurso en estas unidades narrativas menores. Para homogeneizar los procedimientos de criba y agilizar la catalogación en un índice de motivos, esta distribución en motivos caballerescos se organizará a partir de sustantivos deverbales elegidos desde la perspectiva de la acción e indicados en este artículo entre comillas (Bueno Serrano, 2007).

Los episodios bélicos se articulan en secuencias muy repetitivas, con tres momentos en interacción constantes - causas, desarrollo y desenlace-, ya que la hostilidad inicial se transforma en un rebrote violento por el que la coerción, la coacción y la injusticia dejan paso al castigo y al restablecimiento del ordo caballeresco, auténtica tabla de medida del quehacer del caballero. 
Las líneas siguientes servirán para analizar la función de los combates individuales en los libros de caballerías. Son insustituibles, en este sentido, los trabajos de Cuesta Torre, recogidos en la bibliografía final, que, además de ofrecer un análisis minucioso de los combates individuales y colectivos, y de explicar sus causas y variaciones, dan las claves para precisar su significado y su función ética, histórica y narrativa. No insistiré, por conocidas, en sus conclusiones, aunque acudiré a ellas en varias ocasiones.

He decidido seleccionar al hilo del discurso algunos ejemplos que tratan la venganza de las ofensas y la salvación del honor para demostrar la contribución que desde la perspectiva de estudio de las constantes de contenido, que teóricamente se han llamado motivos, puede hacerse para desentrañar la compleja, y a veces alambicada, poética de lo caballeresco. Serán especialmente interesantes aquellos usos que no se ajustan en la forma o en la función a las recurrencias indexadas, y otros que sean ejemplares de rituales de época. Son, por tanto, pequeñas calas en las profusas realizaciones del combate individual caballeresco.

Conviene precisar que este enfoque no es un argumento a favor de la declaración del canónigo toledano de que todos los libros de caballerías son iguales. En efecto, si es importante tener en cuenta el paradigma o el motivo aislado para cuantificarlo -punto de vista adoptado por el canónigo en su crítica-, mucho más lo es estudiarlo en su combinatoria, en el sintagma; cada libro usa los motivos según sus intenciones, y su significado último recae en la sucesión de motivos. Aislados, estos pierden parte de su función documental e interés deontológico.

\section{EL COMBATE PARA SALVAR EL HONOR Y VENGAR LA OFENSA}

En un momento en el que el acto de desafiar es en sí mismo el detonante de la disputa, el conflicto épico-caballeresco surge en los libros de caballerías de inmediato. El desafío daña el honor de un noble, en igual medida que la injuria, agresión pública por humillaciones físicas o morales con violencia, fuerza, exceso y crueldad - , gratuita, sin provocación previa o como mala costumbre.

El afán vindicatorio posterior a la injuria desencadena combates colectivos o individuales - que en ocasiones tienen, por antífrasis, resabios de las viejas ordalías altomedievales - para limpiarla con sangre. Los desagravios se desarrollaban conforme al derecho y buscaban impartir justicia a manos del propio injuriado o de su representante, en este caso en respuesta a una demanda o solicitud del agredido (en el índice de Thompson corresponde a los motivos P525.3. The nearest to blood of slain man must avenge his death y M161.2. Vow to revenge/himself/, king, friends, father or die).

En la etapa medieval el desafío y los preliminares del combate para vengar públicamente una injuria o atentado contra el honor nobiliario eran bastante morosos, con un interminable ritual, muchas veces puramente retórico, codificado en la legislación y en los tratados teóricos del xv; en los textos caballerescos los mecanismos del desafío tienen las mismas etapas y repercusiones "económicas, materiales, 
sociales, ideológicas, festivas y por supuesto culturales" (Cacho Blecua y Marín Pina, 2009: 198), si bien se aligeran bastante los tiempos. El combate es el mecanismo de control por excelencia y, en la mayor parte de las ocasiones, goza del beneplácito de las disposiciones legales contemporáneas y del ius commune, a los que se recurre buscando concordia entre los litigantes.

En los libros de caballerías los conflictos desencadenados por la injuria están protagonizados por personajes de linaje noble, que aspiran a la venganza pública de la ofensa y a la recuperación ante testigos de la honra arrebatada con la agresión. En la época se condenaban de facto las peleas secretas y clandestinas, sin espectadores, y los ataques traidores y sin el ritual previo de desafío que, según el Ordenamiento de Toledo de 1480, comenzaban a generalizarse a finales del xv como consecuencia, decían ellos, del contacto con los mudéjares. En cambio, en los libros muchos enfrentamientos tienen lugar en espacios distantes de la ciudad y de la corte, en islas alejadas, gobernadas por gigantes, o en florestas, sin más testigos que la voluntad de los participantes y la confianza en la legitimidad de la demanda. Esta libertad en el desarrollo alentaba el espíritu aventurero de los receptores, aumentaba la atracción por lo oculto y encarecía la labor del caballero.

Aun a riesgo de simplificar un asunto bastante complejo, podrían distinguirse en el combate dos bloques: el combate deportivo o de campo cerrado, y el no deportivo o de campo abierto. La primera distribución agruparía torneos y justas, juegos de cañas, sortijas, bohordos, "estafermos", corridas de toros, armas retretas, etc. como medios de entrenamiento, más o menos casuales y secundarios, y como formas de entretenimiento y exhibición en espectáculos públicos y movimientos de corte. Estas mismas funciones podrían tener los pasos de armas, en general espectáculos públicos que en los libros de caballerías tuvieron a veces carácter privado, y los rieptos en su vertiente de intercambio retórico de correspondencia, sin aspiración a la lid porque entre los contrincantes no había odio ni deseo de venganza. Los combates deportivos añaden a su función formativa una dimensión lúdico-festiva, que acaba rebasando los estrechos límites de la prosa para entrar a formar parte de otros géneros e, incluso, de prácticas contemporáneas, consecuencia de la atmósfera caballeresca y del ambiente cultural europeo revitalizado en las últimas décadas del Quinientos.

Con independencia del tipo de lucha, lo común era la existencia de una serie de movimientos constantes con cambios procedentes de la distinta combinatoria de elementos constantes. Para Martín de Riquer (1980: 54) la lucha tenía bastante de espectáculo recurrente con un número fijo y, hasta cierto punto, predecible de movimientos. Heredados de la literatura medieval francesa y de las versiones castellanas del XIV, estos golpes se modifican - se suprimen algunos movimientos, se alteran sus relaciones y se añaden otros nuevos - buscando la emoción y evitando la monotonía (Cuesta Torre, 2002: 527). En último término, Martín Romero (2006) afirma que la descripción del combate se convirtió en un ejercicio estilístico para calibrar la destreza del autor como narrador. 
De forma muy general, hay dos momentos importantes: la caída del caballero del caballo y el paso de la lanza a la espada. El movimiento inicial de todo combate es la embestida a la carrera; el caballero, con la lanza baja (so braço, so sobaco, enristrada, etc.) y su caballo al galope, golpea al contrincante y entonces a) o rompe su lanza contra el pecho del adversario que cae al suelo y no puede levantarse o b) se levanta inmediatamente o c) no cae al suelo o d) caen ambos al suelo o e) falla el golpe. Estas cinco posibilidades traen, a su vez, asociadas sus propias combinaciones, de modo que estos elementos se multiplican dando la impresión de que cada una de las luchas es única. Así, si se rompe la lanza en el adversario y este no se levanta, puede deberse a que a) está inconsciente y tienen que quitarle el yelmo para airearlo, b) está muerto, c) tiene el caballo encima y $c_{1}$ ) lo ha dejado herido o $c_{2}$ ) lo ha matado con la caída. Por lo común, con la caída del caballero y la ruptura de la lanza se cambian las armas por la espada, el cuchillo, la daga, el martillo, la maza, si participa algún gigante (F531.4.5.1. Giant with iron club as weapon), o la capelina en el caso de villanos. Las opciones se reducen en el desenlace pues o 1) el caballero se rinde (pide perdón, se transforma en amigo del rival o se convierte al cristianismo) o 2) muere, todo ello contando con que en la mayor parte de las luchas el héroe está en inferioridad de condiciones. ${ }^{3} \mathrm{El}$ triunfo sobre una fuerza superior y desorganizada -reflejo del caos del rival en un momento en el que se valoraba la organización como proyección de la voluntad divina- llega a ser una constante porque el contrincante o era más fuerte que el héroe o más numeroso o iba mejor equipado (L325.1(B) Victory over superior force: one against many; L310. Weak overcomes strong in conflict). En la base de esta distribución se proyecta la creencia de que Dios está de parte de la causa con más razón, derecho o justicia. De este modo, no era tan importante "la cantidad como la calidad y la buena disposición de los caballeros." (Cuesta Torre, 1999b: 117), tanto o más fuertes cuanto Dios apoya al más justo y acentúa sus cualidades.

\section{LOS ELEMENTOS DEL COMBATE SINGULAR}

Las causas, los objetivos o intenciones, las formas del desafío y su difusión, el lugar, los lidiadores (aventureros y mantenedores), los personajes secundarios (fauretes o reyes de armas, trompetas, jueces de campo, heraldos, etc.) o las armas clasifican la lucha. En los libros de caballerías de este primer periodo, es decir, los publicados en la hora de Cisneros, hay varias realizaciones del combate individual, para cuya denominación se han empleado en los textos mecanismos similares a los usados en el tratamiento de otros temas.

Propongo, a continuación, una tipología construida a partir del modo en que se ha llevado a cabo el desafío o teniendo en cuenta su función.

\footnotetext{
${ }^{3}$ Véase también Lucía Megías (1996) y, por supuesto, Cuesta Torre (2002).
} 


\subsection{Los carteles de requerimiento de batalla judicial}

Una de las posibilidades del combate individual son los desafíos verbales, directos e inmediatos o a través de embajadas, mensajeros, cartas en primera instancias $\mathrm{y}$, en segunda, carteles de desafío por medio de fauretes o reyes de armas. Estos medios son los prolegómenos para publicar cualquier clase de lid (paso de armas, duelo judicial, combate singular, riepto), y vienen a dar muestra del ambiente cultural europeo, impregnado de un espíritu caballeresco que se convirtió, a veces, en una forma de vida y un medio no casual para la resolución de los conflictos de honra entre el estamento nobiliario ${ }^{4}$.

El término cartel de desafio es empleado en dos ocasiones en el Floriseo (2, 4, 168; $2,9,181)$. En la primera, Fernando Bernal se refiere al matrimonio entre el duque de Atenas y la hermana del duque de Tebas, aquella que Floriseo había casado después de ser barragana o manceba del duque durante varios años. Este matrimonio había sido una insubordinación civil porque el soldán, al que el duque de Atenas servía como vasallo, le había ordenado que contrajese matrimonio con una sobrina suya, a la que Artemisa, una dueña brava, quiere vengar. Este cartel de desafío es escrito en respuesta a la petición de venganza de Artemisa a un gigante, Architraco, contra el duque de Atenas. Su voluntad está en afrontarlo, pero también en afrentarlo porque lo injuria con la falsa acusación de haber prometido matrimonio a una doncella doce años antes. El gigante desafía al duque con un cartel, y Floriseo responde aceptando ser su representante en el combate, con lo cual parece concluirse que en los libros de caballerías, frente a los usos contemporáneos que he tenido en cuenta, el caballero podía, a la vez, representar legalmente a una mujer y a otro caballero. En la descripción de este episodio se observa una reducción progresiva del número de motivos folclóricos y la consolidación de los caballerescos.

Bernal transcribe el cartel de desafío enviado por el gigante en estos términos:

El gigante Architraco, señor de la Ínsola Temerosa, a ti, el duque de Atenas, hago saber cómo yo oí en mi tierra el gran valer de la señora Artemisa e supe cómo tú la tienes enojada. E porque yo desseo servirla, vine a este su castillo por hazerla satisfecha a ti. Por tanto, yo te combido e llamo para que vengas a combatir comigo, pues que yo en su nombre te combatiré cómo tú usaste con ella como mal cavallero en faltarle una palabra que le diste e no la compliste. E si tú no podrás, embía algún cavallero que en tu nombre se combata comigo en este castillo porque en lugar do erraste conozcas tu yerro, llevando la paga por él mereces.

El gigante está engañado ("mal sabido", según Floriseo), como ocurre en otros combates en los que las dueñas o doncellas dicen "medias verdades" para captar la benevolencia de los incautos caballeros andantes. Pero su demanda y su empresa, si

\footnotetext{
${ }^{4}$ En este sentido Garcia (2001) analiza una carta de desafío o batalla (1413-1414) entre el conde don Fadrique y Juan Álvarez de Osorio. La función de la misiva es doble: por un lado, 1) presenta la retórica habitual del género epistolar y muestra la gran cantidad de documentos que acompañan un desafío, y 2) ayuda a conocer la práctica real de la caballería, que ocultaba con este armazón retórico los problemas derivados de las luchas de poder entre dos tipos distintos de nobleza. Más tardía y de mayor repercusión política son los carteles de desafío que se cruzaron Alfonso V de Portugal y Fernando el Católico (Sesma, 1978) o la famosa rivalidad entre Carlos V y Francisco I (Cacho Blecua y Marín Pina, 2009). Riquer, en sus conocidísimos trabajos, fue el primero en aportar datos que no harían más que ampliar esta nómina.
} 
leemos atentamente, se justifican no tanto porque el duque haya roto el juramento dado a una desconocida, como porque tiene enojada a la dueña brava. La parienta de Artemisa no ha sido requerida en amores, así que el duque no le ha faltado a ninguna palabra y no tiene sentido el enfado. Floriseo no puede ser más drástico ni su argumentación más irrefutable: aun en el caso de que el duque hubiera hecho su promesa sin cumplirla, el matrimonio es imposible porque pertenecen a distinta religión (T131.8. Different religion as obstacle for marriage $)^{5}$.

"Y esto digo porque, aunque el duque os diera essa palabra, no pudo dárosla, pues él era cristiano y essa señora dezís que es gentil; e que la diesse, no era ni es obligado a cumplirla" (Floriseo, 2, 4, 168).

Architraco se enfrenta de buena fe, con la creencia de que en su desafío lleva razón y, por lo tanto, tendrá la victoria de su parte; lucha para paliar el enfado de la dueña quien está, en verdad, airada.

La segunda parte del cartel enviado aporta información relevante. El gigante le dice al duque: “E si tú no podrás, embía algún cavallero que en tu nombre se combata comigo en este castillo porque en lugar do erraste conozcas tu yerro". Como regla general, en los desafíos solo podía usar un sustituto en la batalla el desafiador, no el desafiado, de modo que, en principio, podría pensarse que nos encontramos ante una licencia poética que convierte al caballero en un individuo sometido a un código social y a otro literario, que acaba imponiéndose. Sin embargo, la declaración del gigante puede explicarse porque en los fueros, las Partidas y el Fuero Real, el agredido tiene la prerrogativa legal de imponer las condiciones de la lucha, privilegio al que se acoge y que administra con justeza el gigante al proponer al duque que envíe un representante o campeón. Fija también en el cartel como campo el castillo de Artemisa "porque en el lugar do erraste conozcas tu yerro (...)". Aquí termina el cartel sin ninguna mención al divisar las armas, que le correspondería elegir al agresor. El gigante ha hecho el desafío, impuesto sus condiciones y repartido los papeles. Ahora debería llegar a oídos del duque la noticia de la lucha, responder y hacer las concordias. Pero, en principio, estamos ante un cartel y no una carta de batalla, y las condiciones tendrían que ser distintas.

Por casualidad, Floriseo llega a la isla y, tras mostrar su voluntad de participar en el combate, toma dos decisiones sucesivas: a) fingir ser el duque de Atenas, ocultando su identidad tras las armas ("Ocultación de la identidad por uso de disfraz"; K1810.1.2(B) Exchange of clothes to affect disguise /to disguise) y b) ante la negativa de Artemisa, decide darse a conocer ante el rival y luchar en representación del duque, su amigo (M161.2. Vow to revenge /himself/, king, friends, father or die). En este combate judicial por "Falsa acusación de alevosía" por el incumplimiento de una palabra de matrimonio, el gigante muere por defender a la dueña, una posibilidad que Floriseo había intentado evitar convenciendo a Artemisa. Pero aquella, como su homónima latina (Diana) - la mayor parte de los nombres en el Floriseo son palabras fonosimbólicas - ,

\footnotetext{
${ }^{5}$ Una posibilidad de salvar este escollo sería la conversión al cristianismo por amor de la mora. El tipo de la mora enamorada a la manera de la épica Zaira venía a ser un rasgo de nobleza de carácter que en este episodio no se tiene en cuenta porque los intereses van en otro sentido.
} 
es vengativa y colérica, y no quiere resolver el conflicto por trato, aunque finalmente acabe cediendo. De este modo, mediante la "Asignación de tareas al pretendiente como venganza por desamor", logra convencer al gigante de que participe en el combate a cambio del compromiso de casarse con él. Muerto el pretendiente, la dueña, también giganta, lanza su ira contra el caballero, quien finalmente logra templarla y firmar las paces ("Transformación del enemigo en amigo"; P310.5. Defeated enemy tures true friend; R74.1. Defeated enemy tures conqueror's best friend). En este episodios nos encontramos, de nuevo, con la estructura que usó Montalvo en el Amadís de Gaula, concretamente en la aventura de Angriote, Grovenesa y Gasinán: tres historias enlazadas en la forma, en la función y en el desenlace, y donde la resolución de la primera pasa por las otras dos.

Como Montalvo, Bernal construye un esquema tripartito en torno al motivo de la "Transformación del enemigo en amigo" a través de la técnica del paso de la enemistad a la amistad. El duque de Tebas, hermano de la barragana del duque de Atenas, es enemigo de Floriseo al principio porque desembarca en su isla sin permiso. Con la promesa de que casará a su hermana, consigue el perdón y la ayuda del noble. En este momento, va a Atenas y lucha contra el duque, quien, como su enemigo, es vencido pero, como el griego es un buen caballero, se hace también su amigo, desairando con su conducta al soldán. Este comportamiento no queda en suspense, sino que Bernal lo retoma en otra aventura y consigue, con la amistad de Artemisa, la reconciliación con el gobernante. Pero, frente a la estructura de Montalvo en la que la contrapartida al héroe era nula y no tenía sentido más allá de una satisfacción ético-moral, Floriseo con su auxilium et servitium va consiguiendo aliados que colaboren con él en la gran batalla final. La misma estrategia usan otros descastados, como Amadís de Grecia o Florisando.

El término cartel aparece, pues, en dos ocasiones en el Floriseo (en 2, 9, 181 la segunda) ${ }^{6}$, y por el uso y el contextos tiene una función similar a la carta de batalla, de la que el cartel, según la acepción más empleada por la crítica, es uno de los elementos. Esta identificación de funciones es una propuesta que merece, cuando menos, una mínima reflexión. Las cartas son mecanismos públicos de desafío, leídos de viva voz por los mensajeros, con una retórica perfectamente codificada, heredera de las artes del dictamen medieval y deudora de sus tópicos (Orejudo, 1993: 33-46). Este intercambio de correspondencia incluía, al menos, dos cartas, una de desafío y otra de aceptación, a las que se aconsejaba brevedad, claridad y verosimilitud, cualidades asociadas a la tendencia hacia el estilo marcial. Luego estaban los carteles, distribuidos y fijados por los subalternos. En su acepción general, los carteles se pegaban en diversos lugares para dar noticia o vocear el desafío más allá de los testigos de la lectura de las cartas. En resumen, venían a ser un edicto o un bando que buscaba hacer público un desafío, deportivo-festivo o no deportivo. Tenían como particularidad estar firmados por los mantenedores, que expresaban su conformidad, y por aventureros. Pero ambas características - el ser públicos e ir firmados - no están en el episodio descrito. Con estos datos, ¿estamos en el Floriseo ante un cartel de desafío o ante una carta de batalla, y

${ }^{6}$ Indico libro, capítulo y página, según la edición recogida en la bibliografía final. 
el autor ha confundido el nombre? De hecho, no sería extraño porque el término cartel era un neologismo en castellano, importado de no se sabe muy bien dónde.

El texto habla de cartel y no de carta, tal vez porque: a) las condiciones del combate ya estaban impuestas a fortiori, de modo que no había ninguna posibilidad de negociación o concordia porque el fragmento no abre un diálogo sino que impone una orden; b) no hay, pues, intercambio de misivas y la brevedad, sencillez y llaneza de la argumentación son más propias del cartel que de la carta. Sin embargo, ni uno ni otro son argumentos concluyentes porque $b_{1}$ ) el deseo de Architraco era que Artemisa mandara el cartel al duque, con lo cual, este acabaría respondiéndole, y $\mathrm{b}_{2}$ ) pese a la brevedad, el discurso sigue la estructura de las artes dictamini.

El problema es, sin embargo, mucho más sencillo porque el error está en la acepción usada y en la dificultad para rastrearla (de hecho, Covarrubias ni lo menciona). En el DRAE de 1729 se identifica la carta de batalla con el cartel ${ }^{7}$, al que se describe como "papel escrito o mensaje por el cual uno desafía a otro para reñir con él, y batallar cuerpo a cuerpo en el paraje o sitio que eligiera, ahora sean solos o con padrinos". Esta acepción procede del uso del término en el Ordenamiento de las Cortes de Toledo de 1480:

\begin{abstract}
Vna mala vsanza se frequenta agora en nuestros reynos, que quando algund cauallero o escudero o otra persona menor tiene quexa de otro, luego le enuia vna carta, a que ellos llaman cartel, sobre la quexa que dél tiene, e deste e de la respuesta del otro uienen a concluir que se salgan a matar en lugar cierto, e cada vno con su padrino o padrinos o sin ellos, segund los tratantes lo conciertan; e por que esto es cosa reprouada e digna de punicion, ordenamos e mandamos que de aqui adelante persona alguna, de qual quier ley o estado o condicion quier sea, no sea osado de fazer, ni enuiar los tales carteles a otro alguno, ni gelo enuie a decir de palabra; e qual quier quelo contrario fiziere, que sean dos o muchos, cayan e incurran por ello en pena de aleue, e ayan perdido e pierdan todos sus bienes e sean para la nuestra camara, e el que rescibiere el cartel e aceptare la respuesta, aya perdido e pierda todos sus bienes para la nuestra camara, avnque el trance e pelea no uenga en efecto; e si dello se siguiere muerte o feridas, que si el requestador quedare uiuo dela requesta o trance, muera por ello; e si el requestado (...). (Cursiva añadida).
\end{abstract}

Según esto, el gigante no propone un combate entre caballero sino una resolución privada.

\footnotetext{
${ }^{7}$ En verdad, las diferencias formales y funcionales del cartel y la carta son mínimas. En Lisuarte de Grecia $(38,78)$ leemos la siguiente carta de batalla: "Yo, el rey Armato de Persia, enemigo de mis enemigos, amigo de acrescentar la ley de mis dioses, en fin de mi vejez soy venido sobre esta gran ciudad, con todo este poder de gente que traygo comigo, como principal conquistador del imperio Griego. Digo a ti, el Emperador de Trapisonda, como principal socorredor, que aunque mis días no lo demandan, pues tú assimesmo como yo no fallesces d'ellos, que pues aquí somos venidos, si tú quisieres comigo entrar en campo, yo lo haré, no a fin de otra cosa sino por provar nuestras personas, pues nuestra venida fue para ganar honra. Responde lo que querrás a mi demanda." Explícitamente se pide respuesta, condición no resuelta en el Floriseo que llama a la batalla. "El gigante Architraco, señor de la Ínsola Temerosa, a ti, el duque de Atenas, hago saber cómo yo oí en mi tierra el gran valer de la señora Artemisa e supe cómo tú la tienes enojada. E porque yo desseo servirla, vine a este su castillo por hazerla satisfecha a ti. Por tanto, yo te combido e llamo para que vengas a combatir comigo, pues que yo en su nombre te combatiré cómo tú usaste con ella como mal cavallero en faltarle una palabra que le diste e no la compliste. E si tú no podrás, embía algún cavallero que en tu nombre se combata comigo en este castillo porque en lugar do erraste conozcas tu yerro, llevando la paga por él mereces." Aunque ambos escritos tienen partes que se corresponden, lo cierto es que la diferencia está en la oposición entre "Responde lo que querrás a mi demanda" y la bravatada del gigante "(...) porque en lugar do erraste conozcas tu yerro, llevando la paga que por él mereces", en el fondo, entre la sugerencia y la orden.
} 
Idéntica función que el cartel cumplen las embajadas con cartas de desafío, en ocasiones cartas de creencia (H242. Credential tests: proof that messenger comes from certain person; H82. Identifying tokens sent with messenger) porque, como aquel, son a) provocaciones públicas - sobre todo, leídas en voz alta - y b) medios para concertar un combate. Y con "Desafío a un combate" o "Embajada para desafío a un combate" el campo de referencias se amplía con un resultado interesante. En una ocasión está el motivo en el Amadís de Gaula $(3,68,1242)$ y otra en el Florisando $(222,218 \mathrm{r})$. En el Lisuarte de Grecia hay un salto cuantitativo, y pasamos a cuatro ejemplos $(8,27 ; 37$, 77; 41, 79; 80, 188), los mismos que en el Floriseo (1, 17, 34; 1, 52, 94; 1, 63, 115; 2, 25, 217). Con estos datos nos damos cuenta de que las cartas de batalla son una estrategia del ciclo de los amadises y que Silva explota profusamente materiales preexistentes, que acaban incorporados al paradigma del género y añadidos a textos posteriores, al margen de que pertenezcan o no a la misma serie. Dentro de los desafíos por carta, esta queda reproducida entera, llegando a ocupar un capítulo aparte y aun a salir en la tabla de materias (por ejemplo, Sergas, 148, 701; 164, 752), un rasgo que no comparte el cartel.

El cartel participa de la morfología de las cartas de desafío o de batalla que, como documentos con valor judicial, tienen una estructura prefijada y una retórica propia en torno a las siguientes constantes extraídas del cartel del Floriseo: identificación del que emite el desafío; identificación del que solicita venganza; justificación del desafío; identificación del receptor; condiciones de la lucha expresadas por el desafiador: lugar, hora, armas, participantes, etc.

\subsection{El combate judicial como remanente de las ordalías rituales altomedievales}

Manifestaciones de la intervención de Dios en los asuntos de los hombres, en los libros de caballerías los combates judiciales (H218. Combat judiciaire) no tienen carácter subsidiario como ocurría en los fueros. Ordalías o iudicum Dei, las luchas convierten a la espada, por su similitud con la cruz - analogía empleada ya en la Biblia, y revitalizada por Llull y don Juan Manuel - , en palabra de Dios, con la conciencia plena de que la divinidad hablará a través de ella y de que solo se pondrá del lado de la causa con más derecho. En el fondo está latente la noción de guerra justa de la que hablara san Agustín y de la que se hiciera eco santo Tomás en su Summa theologica, la misma que comparten rieptos y combates singulares. Las lides judiciales son combates a ultranza, que duraban hasta que uno de los dos combatientes muriera o se declarara vencido, en un espacio habilitado al efecto en el territorio de uno de los rivales. Previamente, los caballeros piden seguridad para entrar en terreno enemigo ("Petición de seguridad para participar en un combate").

En relación con estos motivos, es importante señalar que, frente a los libros de caballerías en los que los combates judiciales se toman como prueba de verdad trascendente e irrefutable por su tendencia a focalizar la acción en la actividad del caballero, en la realidad tenían carácter secundario, posterior a la comparecencia legal; “(...) sirven para afirmar o negar una interrogación. Representan la 'verdad', pero no 
los hechos y, además, están formalmente más cerca de la sanción y de la venganza" (Madero, 1992: 46). De este modo, las ordalías funcionaban como prueba única en homicidios, riñas con tumulto y muertos, en el hurto de más de veinte sueldos y en el caso de relaciones sexuales entre criados y amas.

Como marcas de sexo, eran de tres tipos: lid o combate judicial, jura e hierro caliente. Las ordalías bilaterales o combates judiciales eran exclusivamente para los hombres. Bajo la fórmula pari suo respondere, se convocaba el combate según unas normas codificadas por ley (participantes, ausencia o no de reto previo, días de celebración y duración [tres en todos los casos]). Originario de tribus germánicas (Ziegler, 2004), el duelo judicial consistía en que el agraviado o acusado tiraba un guante a los pies de los jueces indicando con ello que quería defenderse de la acusación mediante el combate. El retador puede luchar a través de un sustituto, si bien el retado debe participar sin posibilidad de sustitución en el duelo.

Así pues, durante las primeras décadas del siglo xvi habría que usar el término ordalía con bastantes precauciones porque resulta anacrónico como tal desde hace tiempo. En el contexto de los libros de caballerías castellanos este marbete denominaría a la acusación de traición o alevosía cuyo juicio se remite a las armas que se admiten como pruebas de verdad. Teniendo en cuenta estas restricciones, en los siete libros de caballerías analizados he localizado en total cuarenta y tres imaginarias realizaciones de los motivos folclóricos H218. Trial by combat. Guilt or innocence established in judicial combat; H218.0.1. Vindication by champion. Usually noble lady or king accused; $\mathrm{H} 220$. Ordeals. Guilt or innocence thus established.

Estos mecanismos probatorios se someten, sin embargo, a revisión y se ponen en duda en los propios textos caballerescos. Además, si se usan, se reducen, remitiendo a los hitos más importantes, a su parafernalia legal y retórica porque lo único importante es el resultado de la mano del caballero. En el Primaleón $(29,60)$ Rifarán llega a la villa de Islandia, tierra de una condesa homónima, heredera de todo el patrimonio del marido. $Y$ " d'esto ovo muy gran pesar un hermano del Conde, que se llamava Dioles", quien piensa que la herencia "a él venía de derecho" porque "ella avía fecho traición a su marido por onde avía perdido lo qu'él le dexó" (id.). Dioles muere en el combate judicial contra Rifarán y, a partir de entonces, la condesa y Rifarán "cada noche estavan en uno" (id. 62), confirmándose de facto que las sospechas de deshonestidad del cuñado no eran gratuitas y que las ordalías dejan de ser efectivas. Esta manifestación del derecho irracional es ahora presentada desfavorablemente; la ordalía deja de considerarse un medio perfectamente adecuado y honorable para refutar falsas acusaciones de traición, y se pone en cuarentena para resolver problemas sustanciales sobre el derecho, la política y el honor nobiliario.

Frente a otros motivos, la "Ordalía por combate singular" aparece en todos los textos analizados como mecanismo narrativo para zanjar el conflicto y como pruebas de verdad ante la débil palabra del hombre. En ella pervive la conciencia

\footnotetext{
${ }^{8}$ Se encontraría aquí el motivo de la 'reina injustamente injuriada', como le ocurrió a la reina Sevilla, a Isomberta -la madre del Caballero del Cisne- y la madre de Palmerín de Olivia.
} 
de que, junto con el juicio del caballero y del gobernante, grita la voz de las armas, que acaba imponiéndose sobre las otras porque es, en cierta medida, palabra de Dios y la forma más rápida de administrar justicia. Sin embargo, una y otra manera de actuar no son excluyentes, de modo que ante una "Embajada para emitir quejas ante el gobernante" es posible que este no dictamine sentencia y solo imparta justicia. Antes de la celebración de la lucha, era conveniente que el rey o emperador estuviese al tanto de la intención de los litigantes e intentase evitar el conflicto. Por sus objetivos y función existe la necesidad de que los combates judiciales tengan testigos y documentación que acrediten la voluntad de lucha, las causas, el lugar, la concordia de los lidiadores, etc. De hecho, los participantes, las condiciones del enfrentamiento y del campo, y su carácter público convierten el espacio cortesano y urbano en el lugar idóneo para su desarrollo porque el combate debe ser público, como lo fue el desafío, para que el resultado, vinculante siempre, sea conocido y surta los efectos oportunos, es decir, restituya la honra perdida y vengue la afrenta.

Los elementos en el desarrollo son P557.4. Customs concerning single combat que se realizan según las siguientes constantes:

- Partición del sol para evitar que solo uno de los lidiadores sufra sus inconvenientes;

- Dictamen de los jueces de campo o escribanos;

- Enumeración de las condiciones:

- Prohibición de entrar en el campo para ayudar, para evitar así la H218.3(B) Rules of single combat broken;

- Disposición de tiempo límite de desarrollo (Z72.0.1(B) Year time limit on quest /adventure/);

- Uso de armas nobles, lanzas y espadas;

- Inicio tras el sonido de trompas o añafiles, o señal del rey o de los jueces; si comienza el encuentro sin que haya una señal, se pretende mostrar la impaciencia de los caballeros por luchar, lo que puede ser indicio de soberbia o de gravedad del asunto tratado (Palmerín de Olivia, 148, 325, entre otros; W212. Eagerness for combat; F1041.8.6. Men go mad in battle);

- Habilitación de un terreno cercado. Prevalece la conciencia de que los contrincantes deben estar aislados para evitar ayudas externas, distracciones por el ruido de los cadalsos, etc.;

- Designación de los participantes, el mismo número en cada uno de los bandos. Los gigantes suelen pedir enfrentarse con más de un caballero a la vez pero, en general, sus peticiones son desatendidas. Cuando son aceptadas, acaban duramente vapuleados, incluso muertos.

Los cuarenta y tres combates judiciales imaginarios mencionados se reparten de forma regular en los siete textos. Diez corresponden al Amadís, nueve al Florisando, ocho al Primaleón, siete al Floriseo, cinco al Palmerín, dos al Lisuarte de Grecia y otros dos 
a las Sergas. Goza, pues, el motivo, adaptado a las nuevas circunstancias narrativas, de gran vitalidad para resolver unos conflictos cuyas causas se encontrarían, entre otras, en las siguientes posibilidades: a) falsedad en la reclamación o acusación; b) venganza por una muerte deshonrosa - $\left(\mathrm{H} 218.3^{*}\right.$. Judicial combat to avenge wrongful death), en tres ocasiones en el Amadís de Gaula, una en el Palmerín y otra en el Primaleón - o por una muerte deshonrosa; c) recuperación de los bienes arrebatados; d) protección y seguridad...

A veces entre nobles, la resolución del conflicto, es decir, la guerra pasaba por combates judiciales que tenían la ventaja de poder reducir el número de personas o contingentes que entran en el conflicto, minimizar gastos y obtener rápidos resultados. No es extraña en la época y en la literatura (en seis ocasiones, una en el Amadís, otra en el Florisando y otra en las Sergas, y tres en el Floriseo) la presencia del motivo de la aristías o la "Decisión del triunfo en la guerra por un combate singular entre los capitanes", descrito en el índice de Thompson como H217.1. Decision of victory by single combat between army leaders. Estas aristías aspiraban a evitar la guerra por razones éticas, religiosas, prácticas y humanitarias (Cuesta Torre, 1998: 104); cumplían una función histórica -minimizar el desembolso económico y el número de muertos (Contamine, 1984: 351)- y otra fundamentalmente literaria, “(...) para ensalzar la figura del héroe, de cuya actuación se hacía depender el resultado (...)." (Cuesta Torre, 1999a: 118).

\subsection{Los rieptos y desafíos}

Como medios para resolver pleitos entre enemigos, vinculados al principio con el concejo, los rieptos poco a poco se convirtieron en un privilegio de los nobles, un medio propio de injuriar a un igual mediante “(...) un acusamiento (...) por corte, profaçandolo de la traycion, o del aleue, que la fizo" (Partida vII, III, I; ratificado en el Ordenamiento de Alcalá, XXXII, VII). Es, en esencia, el riepto un proceso legal de acusación oral en la Corte y ante el rey - el cual, mediante arbitraje, mediaba para evitar el enfrentamiento armado (Valera, Tratado de los rieptos y desafíos) - , que tiene que ver con la infamia o denuncia ante testigos de traición (cuando la agresión afecta al rey) o alevosía (si a otro), únicos supuestos para hablar de esta clase de enfrentamiento en el periodo medieval. El reptado queda por esta acusación pública y verbal afrentado, injuriado, difamado y deshonrado, es decir, el riepto tiene un peso político y social importante e, incluso, llega a convertirse en un estigma sobre el acusado. Como consecuencia, el riepto crea la ilusión de unidad de clase.

En el Florisando el emperador de Roma, al oír cómo el Caballero de la Fortuna acusa de traición a su hijo Arquisil, declara que prefiere verlo muerto antes que menoscabado porque el agravio busca arrojar la infamia sobre el ofendido. El riepto en sí mismo es la acusación pública de traidor o aleve, de modo que, aunque no llegue a celebrarse la batalla, con esta declaración oficial se venga de alguna manera al cuerpo infamado.

Como mecanismo en la resolución de los conflictos, este tipo de combate se articula en tres ejes: 
a. si en el combate judicial la verdad era el objetivo final del enfrentamiento, la mentira es la obsesión. Sigue en este momento vigente el motivo de la "Falsa acusación" con un ligero cambio de perspectiva porque, mientras que antes la sospecha caía sobre el reptado, ahora las miradas se fijan en el reptador. En este contexto el desafío podía realizarse como un riepto y desarrollarse como un combate judicial - si bien, no siempre era así-, ya que con ambos términos se remite a un tipo de lucha en la que se aspira a la confesión pública del delito (Partida VII, III, IV) y al reconocimiento oficial, administrativo y legal de lo ocurrido. Con o sin intervención del rey, los rieptos pueden quedarse en simples ejercicios retóricos o realizarse en forma de duelos judiciales o combates singulares, que acaban convirtiéndose no tanto en una prueba de verdad como en una forma de reparación honorable.

b. "No responder a un riepto podía ser interpretado como un acto de cobardía y corroboraba la verdad de las palabras del riepto" (Madero, 1992: 195).

c. Para que sea efectivo el riepto y se pueda tomar venganza y recuperar la honra perdida es importante que el reptador se desdiga, si ha mentido en la justificación de la lucha, o que el reptado declare su culpa. La derrota del rival, frente a lo que ocurría en el combate judicial, no es vinculante ni trae la venganza ni devuelve la honra, a no ser que en las condiciones previas se especifique este hecho de alguna manera.

Aunque es posible que algunos rieptos lleguen a funcionar como ordalías ${ }^{9}$, lo común es que este tipo de desafíos se resolvieran como un ritual con una importante carga retórica que solo a veces se realiza en una lid pues con la injuria de la acusación pública ya queda consumada la venganza. Si se quería la lucha, existían fórmulas específicas para ello en el enunciado del riepto.

Se trata, pues, de un combate prioritariamente dialéctico porque, aunque triunfe el vengador, la culpa recae en el vencido solo si este reconoce expresamente su comportamiento alevoso. Si no hay aceptación pública, el riepto no ha sido efectivo. Algo similar ocurre en el episodio en el que el Caballero de la Fortuna (Florisando, 178, 187r) acusa a Arquisil de haber cometido adulterio con Floriana, hija de Angriote d'Estraváus. La acusación es verdadera pero está mal enfocada pues el adulterio ha sido cometido con Helisena, la hija de Amadís de Gaula. Arquisil lucha y vence al Caballero, quien se niega a retractarse de la acusación en la que basaba su riepto.

A pesar de que Otero (1959) opine que el riepto no fue legislado hasta las Partidas y el Fuero Real, parece ser que en los fueros locales se hacía mención a este proceso

\footnotetext{
9 “(...), en el riepto municipal y en el de las Partidas de los siglos XIII y XIV existen elementos de la ordalía, de la injuria y de la venganza, articulados en formas y grados variables. Entre estos tres aspectos hay una identidad parcial de mecanismos, en la medida en que la ordalía, la injuria y la venganza pueden ser leídas como relaciones sociales que exigen la presencia de lo público y que se definen por las formas de poder" (Madero, 1987: 808). En cambio, Otero Valera niega que el riepto funcione como ordalía: "Además, el propio hecho de no bastar que fuese vencido el reptado para ser dado por traidor, sino ser necesario que él se desdijese en el campo, muestra por sí solo que este duelo no era un juicio de Dios o un acto destinado a invocar su testimonio" (1959: 73).
} 
con anterioridad. Es cierto que la legislación de Alfonso X le dio carta de legalidad y definió sus formas ritualizadas. En el xv se volvió a revisar su configuración en diversos tratados teóricos, como el Tratado de los rieptos y desafíos de Diego de Valera, que, siguiendo a las Partidas, concluye:

(...) que todo fijo dalgo que quisiere a otro reptar, lo deve primero fazer saber al rey en secreto (...). Y el rey le deve responder si puede levar este fecho adelante; e aunque el tal le diga que sí, el rey le deve amonestar y consejar que se venga con su adversario, dándole para ello plazo conveniente; en el qual tiempo si se no aviniere, el reptador deve fazer enplaçar a aquel que quiere reptar para ante el rey.

La acusación, queja o querella debe ser expuesta ante el rey, pues se busca su consentimiento y, al menos, frente a doce caballeros (Partida VII, III, IV) para evitar la "Falsa acusación" o "Falsa jura" (K2100. False accusation) de traición (K2114. Man falsely accused of infidelity/treachery/) o alevosía.

Si bien el perjuro se sancionaba en la época con diversos apercibimientos, esta variante de la infamia a veces - en general, el que retaba en falso, aunque él no supiera su error, moría en el combate - no se castiga en los libros de caballerías de esta primera etapa. De hecho, la acusación más importante, la "Falsa acusación de traición" de la que es víctima Amadís, a pesar de vencer a los menesterosos que lo atacan, no se resuelve ni se aplica justicia sobre ellos, que siguen ocupando un importante lugar en la corte de Lisuarte. Al margen de esta ocasión cuya función es amplia y compleja, la voluntad de la literatura es, en principio, reflejar la estructura ritualizada de una legislación por la que el riepto es la manifestación de la injuria mutua entre los participantes cuya vitalidad ahora se justifica por ser una forma de reparación. Su peculiaridad, sin embargo, está en que lo interesante del riepto no es tanto la retórica como la acción, la lucha. Desde un punto de vista estructural, los rieptos contribuyen a la variatio en el combate y se identifican por la recurrencia de dos formas: a) acusación pública de traición, en relación con el rey, o alevosía en la corte con carácter vindicatorio (P555.8(B) Avenging defeat in battle/single combat/). La acusación puede ser falsa (errónea a veces) o cierta; b) mentís, por el que se acusa al reptador de falso testimonio o perjuro.

El riepto no tiene un uso mayoritario en los libros de caballerías. De hecho, los resultados del rastreo de este motivo son predecibles en cierta medida y su interpretación viene a insistir en la línea apuntada en otras ocasiones. En el Amadís de Gaula hay dos desafíos de este tipo, uno por una acusación de traición $(2,64,937)$ y otro por asesinato $(1,39,597)$, es decir, la presencia de este ritual, adaptado a los límites y necesidades de la prosa, se circunscribe a los libros más próximos o más deudores de las costumbre bélicas medievales.

En el episodio del riepto de Olivas al duque de Bristoya (Amadís de Gaula, 1, 39, 597) el retado es un caballero, de linaje noble, que interviene en la batalla acompañado de otros tres (Olivas, Agrajes y Galvanes sin Tierra). Su desarrollo responde a los estereotipos y formulaciones del ritual en la legislación: Olivas actúa por su “Deseo de llevar a cabo la venganza por la muerte de un ser querido" (P525.3. The nearest to blood of slain man must avenge his death) y se dirige a Londres donde Lisuarte celebra sus cortes 
para emitir sus "Quejas ante el gobernante", que conducen a la "Acusación pública de asesinato" (alevosía) de su primo hermano por el duque de Bristoya. Lisuarte,

Avido su consejo con los que desto más sabían, puso plazo de un mes al Duque que a responder viniesse, y que si por ventura quisiesse meter en esta recuesta dos cavalleros consigo, que Olivas los tenía de su parte tales que con toda igualeza de linaje y bondad podrían mantener razón y derecho (Amadís de Gaula, 1, 29, 518).

El duque es llamado a la corte para que exponga su defensa. Dispone de un mes para acudir allí sabiendo de antemano que el desafío será armado y no verbal, que podrá entrar en combate con otros dos caballeros, sin que en nada desmerezca su nombre porque los rivales son iguales que él en linaje y bondad. Cuando llega a la corte, declara que Olivas es un mentiroso. Todos se retraen y Olivas, solo ante Lisuarte, realiza la acusación formal:

-Señor, el Duque que ante [v]os está me mató un primo un primo cormano, que le nunca fizo ni fixo por qué, y dígole que es por ello alevoso, y esto le faré yo dezir, o lo mataré o echaré del campo (Amadís de Gaula, 1, 39, 597).

Se celebra el combate judicial como venganza sin que haya reconocimiento verbal de la culpa ni declaración de vencido, de modo que, en el fondo, el riepto ha quedado reducido a una venganza claramente expresada por el reptador, Olivas, en su exposición pública del delito ${ }^{10}$ : en su riepto afirma que no necesita que el Duque declare su participación en el asesinato de su primo pues se siente pagado con su muerte.

El significado de ordalía convive con la injuria y venganza en el segundo reto del Amadís de Gaula $(2,64,937)$, aunque el desarrollo queda oculto por las estrategias en la sombra de Brocadán y Gandandel. El telón de fondo es el problema de Madasima y sus doncellas, que vienen a convertirse en chivos expiatorios y cortinas de humo ante la "Falsa acusación de conspiración" de la que es víctima Amadís. Este riepto es más un subterfugio diplomático para ganar el favor de Lisuarte que una declaración procesal conforme a ley. Los participantes son Imosil y Gandandel, y todo queda en un intercambio retórico porque la madre de Madasima muere en medio de las negociaciones, y en esta nueva situación el desafío no tiene razón de ser. El conflicto se complica posteriormente porque la trama oculta de Brocadán y Gandandel es descubierta por los aliados de Amadís, quienes acusan a los consejeros de traidores, dejándolos, de esta manera, ofendidos y agraviados; los acusados piensan que, con el insulto, se ha cometido con ellos una injusticia. Los hijos van más lejos y lo consideran una acción maliciosa y deliberada, gratuita e infamante. De acuerdo con la noción de solidad de grupo, no tienen otra posibilidad que vengar a sus padres.

Aunque la ofensa era personal y no podía ser aceptada más que por el ofendido, un hijo podía sustituir a su padre si éste estaba demasiado débil y era viejo (K3.1. Relative substitutes in contest). En este caso, sus hijos, ignorantes del hecho, reaccionan a la infamia elevando su "Mentís como respuesta ante una acusación de traición" (J1141. The guilty protets his innocence), e infaman con este desafío a los ofensores. Dar el mentís

\footnotetext{
${ }^{10}$ Sobre los paralelismos entre este episodio y las aportaciones de Valera en el Tratado de rieptos y desafío, pueden consultarse las agudas notas de Cacho Blecua en su edición del Amadís de Gaula (p. 518, nota 1; p. 597, nota 8).
} 
es entonces un acto esencial que desencadenaba el desafío, ya desde sus orígenes, en el siglo Ix. El que recibe y emite este desafío siente la ofensa; cuando lanzan sus gajes en señal de aceptación, se invierten los papeles y ambos bandos quedan ofendidos, infamados y deshonrados. "El mentís (...) era la acusación directa de haber pronunciado una mendacidad con la intención expresa de injuriar." (Pérez Cortés, 1996: 112). Esta acción tiene que ver con la importancia de la verdad como valor aristocrático y virtud cristiana y caballeresca, así como mecanismo para adquirir honra y salvar el alma. La fechoría de la lengua que es el mentís solo se limpia con la sangre derramada del ofensor o con la sincera amistad entre los ofendidos.

En el Florisando se retoma la acción de retar con modificaciones importantes, pues, si bien en el Amadís el desafío era producto de una acusación cierta, en el Florisando el Caballero de la Fortuna reta a Arquisil, acusándolo de traidor y aleve, sin atinar del todo en sus afirmaciones - recordemos que Arquisil tiene parte con la hija de Amadís y los hechos ocurren en la casa del rey. En presencia de toda su corte, el Caballero declara que ha visto al joven entrar en la habitación de Floriana. En este momento Amadís recuerda al Caballero las condiciones de cualquier reto (ellos hablan, simplemente, de desafío, pero como la acusación es de traición y alevosía, el proceso era el mismo que en anteriores ocasiones, es decir, un riepto):

1. Lo primero que aquel que es desafiado sea sospechoso de aquella infamia que le es opposita y diffamado della;

2. Lo otro, que no pueda haver otra probança, salvo la ventura de las armas, que si otro hay, yo no daré lugar al desafío;

3. Lo otro, que aquel que desafía sea igual o de mayor dignidad que el desafiado, porque el de menor dignidad no puede desafiar al de mayor (Florisando, 185, 195v) ${ }^{11}$.

La respuesta de Arquisil, hijo del emperador de Roma, es clara ante la acusación del Caballero de la Fortuna:

-En eso mentís- dixo Arquisil- que yo no soy traidor ni nunca Dios quiera que yo entrasse en la cámara de la infanta ascondidamente sin su licencia y mandado ni a folgar con Floriana ni con otra de su cámara. $\mathrm{Y}$ en dezirlo como lo habéis dicho havéis muy malamente mentido (Florisando, 185, 196r).

El emperador de Roma se lleva un gran disgusto por la denuncia, y prefiere ver a su hijo muerto que con el estigma de la traición. El Caballero de la Fortuna muere, no sin antes pedirle el rey Cildadán “(...) que os desdigáis de aquello que ante el rey Amadís y su corte dexistes, o que os otorguéis por vincido d'esta batalla, o que faga

\footnotetext{
${ }^{11}$ Poco después, y por boca del monje Anselmo, Páez de Ribera critica duramente los desafíos y, por extensión, la costumbre de Amadís de Gaula, quien le responde: “- (...). Verdad es que, aunque yo en algún tiempo seguí esta costumbre ni entonces me parecía bien ni agora la alabo, pero allende de la general costumbre, hay leyes y ordenanzas d'este reino que disponen que se pueda fazer el tal desafío cuando el que es acusado niega haver cometido el tal delicto, y el acusador no tiene con quién poderlo provar y ofrece su persona a la batalla, y el acusado assimismo se quiere por batalla salvar, lo cual todo ha sido en este caso" (Florisando, 187, 196r). Amadís justifica su decisión por la costumbre caballeresca; sin embargo, el riepto rebasa los usos caballerescos y queda sometido a la legislación local. Podríamos proponer que estamos ante un tratado teórico novelizado (Florisando, cap. 187).
} 
Arquisil de vos aquello que él más fuera contento". Pero no solo no se desdice, sino que ratifica su acusación:

- (...). Mas esso que dezís que con falsa mentira lo injurié, esso niego, que yo dixe muy gran verdad, puesto que floxamente la defendí. Y por el pago y en pena de mi floxedad bien me puede matar, mas no será mi muerte porque yo, en lo que tengo dicho, haya mentido (Florisando, $191,199 \mathrm{v})$.

La incorporación de este desafío a las páginas del Florisando tiene un objetivo superior a la simple función novelística, pues Páez de Ribera aprovecha la ocasión para criticar estas prácticas, directamente en las palabras de Anselmo o de forma indirecta con la muerte del Caballero, injusta e infamante porque no miente. Se pone, de este modo, en tela de juicio la efectividad de estas resoluciones y se propone, como alternativa, el diálogo:

- (...). E aquellas cosas se digan en plaça que por testigos se puedan provar y no por averiguación de batalla. Y las que por esta vía provar no se pudieren, aunque sean ciertas no las juzguemos, mas júzguelas Dios, que puede traher en la luz las cosas que están ascondidas y alumbra[r] la escuridad de las tinieblas y manifestar los desseos de los coraçones (Florisando, 188, 196v).

En el Palmerín de Olivia se recupera el motivo del reto del Amadís, si bien los términos y los participantes son distintos. De nuevo, estamos ante un acercamiento del ciclo de los palmerines a las estrategias discursivas de los amadises para adscribirse a la tradición de Montalvo. En la adaptación hay cambios que apuntan hacia un contexto solemne y artificial, en el que la corte pasa a ocupar un lugar primordial y el rey o el emperador llega a ser el auténtico protagonista porque el delito es de traición, es decir, afecta a su casa (familia y bienes materiales e inmateriales) y, de alguna manera, él queda injuriado.

En efecto, en el Palmerín de Olivia $(27,63)$ Adrián, tío del rey de Bohemia, ha sido acusado por el conde Domarco de permitir que su hijo Diardo tuviera la intención de matar al rey de Bohemia y alzarse con el reino. Adrián responde a esta acusación: “desde agora te digo que mientes en todo quanto has dicho como falso que eres" (Palmerín, 27, 64), es decir, emite su "Mentís ante un riepto por una acusación de traición ante el gobernante". El carácter legal de la ceremonia se comprueba en la declaración pública del delito, en el mentís y en la voluntad de Palmerín, que quiere representar a Diardo y Cardonia, de que le den el derecho en público, en una ceremonia improvisada - con reminiscencias con algunas del Amadís de Gaula (1, cap. 13) - con un componente legal importante, por la que asistimos a la "Aceptación de la petición de ser el representante en un combate" (H945. Tasks voluntarily undertaken):

-¿Ponéis todo vuestro derecho- dixo Palmerín- en mí y en este cavallero, que lo defendamos por armas en campo?

- Sí- dixeron ellos-. Quiera Dios que vos ayude con la verdad.

Palmerín añade otro matiz a esta ceremonia, innecesario en otros casos porque el arbitraje correspondía a un rey reputado como Amadís o de Lisuarte. Sin embargo, con esta obligación de jura al monarca de Bohemia se pone en entredicho la fe en él:

Palmerín dixo al Rey: 
-Señor, nosotros somos desafiados para entrar en campo. Aquí o no queda otra cosa de fazer sino que vos juréys delante de vuestros cavalleros que si nosotros matáremos o venciéramos al Conde Domarco e a sus primos, que vos soltaréys a Diardo e a Cardonia e daréys por leal a Adrián e ansimismo a ellos.

-Yo lo juro a Dios de lo fazer ansí - dixo el Rey.

-Muchas mercedes - dixo Palmerín. E bolvióse para el Conde e dixole: - Conde, ¿queréys todavía la batalla? ¿Afirmáysvos en lo que havéys dicho? Mirad que ha de ser con condición que nos podamos ayudar los unos a los otros, si menester fuere. (Cursiva añadida).

Palmerín otorga solemnidad a una ceremonia de la que se convierte en juez y oficiante, e incorpora datos de la descripción de la misma que estaban ausentes en otros rieptos anteriores.

Finalmente, también en el Palmerín $(85,178)$ el motivo de la falsa acusación transforma en protagonista a una mujer, Alchidiana, hija del soldán de Babilonia. Mientras Palmerín está en tierra de moros, Alchidiana y su prima Ardemia se enamoran del héroe. Ardemia se declara a Palmerín y él la rechaza. Aquella misma noche muere por desamor ("Muerte por desamor"), y enseguida se difunden rumores sobre la intervención de su amiga Alchidiana en la muerte. Entre los que creen en esos rumores infundados está Amarán de Nigrea que había solicitado a Ardemia como esposa; el caballero reacciona airado ante la noticia y jura vengarse de Alchidiana acusándola públicamente de haber cometido el asesinato por envidia. Amarán llega a la corte, se levanta ante todos, como hiciera el Cid ante la corte toledana de Alfonso VI por la afrenta a sus hijas, y le exige al soldán que haga venir a la infanta para formalizar una acusación no exenta de insultos y comentarios vejatorios ("vos soys donzella e falsa"):

E porqu'estas cosas no se pueden saber el secreto d'ellas sino por juyzio de batalla, - vos soys donzella e falsa -, avéys de dar cavallero que lidie por vos; e qualquiera qu'él sea, yo le faré conocer que digo verdad: que vos soys dina de pena por fazer tal trayción. (...).

Hasta el momento, el desafío se ha realizado a través de palabras, pero también de gestos rituales y aspavientos personales, de movimientos de avance y retroceso, de ascenso y descenso, con valor social e individual (Cacho Blecua, 2009), que en este caso muestran a un individuo que carece de control sobre sus emociones, soberbio y desmesurado.

Propone este caballero moro un riepto que funcione como ordalía bilateral por combate judicial (“E porqu'estas cosas no se pueden saber el secreto d'ellas sino por juyzio de batalla") cuya protagonista sería una mujer, y no un hombre como antes. Ante ello, Alchidiana deja de lado las comedidas razones que los moralistas aconsejaban a las de su sexo. Esta doncella brava emite en persona el mentís y, airada, humilla a su agraviador al animalizarlo y espetarle: "con un palo te faré conocer mi limpieza." (Palmerín de Olivia, 85, 178).

En este caso no hay ninguna explicación sobre las condiciones del combate, pues el riepto aspiraba a mostrar ante los moros que Palmerín es hijo de rey y que ha sido, en cierta medida, prohijado por la reina de Tarsis, quien manda a la corte del soldán un mensajero con esta noticia cuando Amarán pide conocer el linaje de su 
contrincante. Tales prolegómenos anuncian que la acusación de Amarán era falsa y la infanta queda exonerada de culpa.

De este modo, los libros de caballerías usan el riepto según los intereses narrativos, bien como medio de resolución de los conflictos o como crítica a los mismos. En cada uno de los desafíos comentados se da importancia a uno de los aspectos de la acusación pública, de modo que para comprender esta ceremonia habría que considerar los datos sesgados de cada uno de los episodios. Prevalece, no obstante, en el Florisando y en el Palmerín la conciencia de que los libros son algo más que novelas de unos hechos, y sus páginas se convierten en recordatorios o tratados sobre costumbres bélicas (tratados de rieptos y desafíos). En las coplas finales del Primaleón, estudiadas por Marín Pina (2005), queda expresa esta intención: “Aquí se declara de cavallería/dotrina y manera de (...)/ reptar por palabras, saber combatir / a toda persona que aleve fazía / (...) / los reptados muestra ganarse por armas, / ditados por sciencia, / virtudes y genealogía." $\left(\right.$ estr. $\left.3^{\mathrm{a}}\right)$.

En este momento y en el terreno de la literatura los rieptos tienen una estructura que exige un conjunto de disposiciones en el retador y en el retado: a) el riepto tiene dos partes, las palabras y las lides, y a desenvolverse en ambas enseña esta obra; b) la acusación es, según las coplas, de alevosía, un error si tenemos en cuenta que en los dos episodios comentados del Palmerín es declarada públicamente la traición porque los hechos o afectan a la vida del rey o transcurren en su casa; c) los retados se vencen $\mathrm{c}_{1}$ ) con armas, pero también con $\mathrm{c}_{2}$ ) habilidades dialécticas y morales, propias y del linaje porque, según dicen las octavas, en el libro se enseña a estructurar y redactar retos.

En el tratamiento del riepto en los textos mencionados puede observarse un perfeccionamiento con respecto a los usos contemporáneos y una mayor importancia de la figura del rey, paralela a la "cortesanización" del ritual. De ser un conflicto entre caballeros, pasa a ser un medio de resolución de problemas usando caballeros. Los autores emplean esta práctica como elemento de la narración de forma directa, glosando la importancia de los rieptos y criticando sus excesos, o indirecta, mediante la actuación de sus personajes. Las acusaciones que desencadenan el proceso son de traición y alevosía, nunca de ofensas menores. Lo importante es la venganza y, sobre todo, un deliberado deseo de marcar a los culpables porque los "testimonios visuales" son irrefutables.

\section{ALGUNAS CONCLUSIONES}

El examen de un repertorio representativo de combates singulares con desafío previo en los libros de caballerías cuyas primeras ediciones conservadas oscilan entre 1508 y 1516 permiteextraeralgunas conclusiones interesantes, aunqueaún provisionales. Algunos de ellos reflejan con absoluto rigor las costumbres bélicas medievales; otros, en cambio, aun conociendo las fórmulas, sacrifican las formas marciales en aras de las necesidades narrativas, que acaban imperando sobre la tradición bélica. En todos los casos analizados, sin embargo, se superpone el deseo de venganza sobre cualquier 
otro valor secundario, y se aplica una justicia pública que libera la lucha de posibles intenciones aviesas.

Ahora el combate singular es vinculante en la resolución de conflictos, y deja de lado otras soluciones (tratos, renovaciones del pacto feudal, declaraciones de conformidad con la acusación...). Privativamente nobiliario, la lucha crea la ilusión de unidad de grupo, de elemento cohesivo que se debate con libertad entre los usos y la literatura. En este contexto los motivos folclóricos de Thompson y los propiamente caballerescos coadyuvan en la novelización de las costumbres contemporáneas; los datos propuestos demuestran una correspondencia entre motivos y usos históricos. No habría, pues, incompatibilidad entre unos y otros, como evidencia el estudio antropológico.

\section{BIBLIOGRAFÍA}

Alemany, R. et al. (coords.) (2005): Actes del X Congrés Internacional de l'Associació Hispànica de Literatura Medieval. Universitat d'Alicant, 16-20 setembre de 2003, Symposia Philologica, Alacant, 2.

Alvar, C. y J. M. Lucía Megías (eds.) (1996): La literatura en la época de Sancho IV (Alcalá de Henares, febrero de 1994), Alcalá de Henares, Universidad de Alcalá de Henares. Amadís de Gaula = Garci Rodríguez de Montalvo (1991): Amadís de Gaula, ed. J. M. Cacho Blecua, Madrid, Cátedra, 2 vol.

Beltrán, R. (ed.) (1998): Literatura de caballerías y orígenes de la novela, Valencia, Universidad de Valencia.

Boixareu, M. y R. Lefere (eds.) (2009): La Historia de Francia en la Literatura Española. Amenaza o modelo, Madrid, Castalia.

Bueno Serrano, A. C. (2007): “Aproximación al estudio de los motivos literarios en los libros de caballerías castellanos (1508-1516)", en J. M. Cacho Blecua et al. (eds.) (2007): 95-113.

Cacho Blecua, J. M. (2000): “Ejemplos clásicos en el Libro del cavallero Zifar: Antígono, Alejandro y Régulo", Crisol, 4: 93-110.

Cacho Blecua, J. M. (2002): “Introducción al estudio de los motivos en los libros de caballerías: la memoria de Román Ramírez", en E. B. Carro Carbajal et al. (eds.) (2002): 27-57.

Cacho Blecua, J. M. (2005): “La aventura creadora de Garci Rodríguez de Montalvo: del Amadís de Gaula a las Sergas de Esplandián", en C. Company et al. (eds.) (2007): 15-50.

Cacho Blecua, J. M. et al. (eds.) (2007): De la literatura caballeresca al “Quijote”, Zaragoza, Prensas Universitarias de Zaragoza. 
Cacho Blecua, Juan Manuel (2009): “Introducción a los gestos afectivos y corteses en el Amadís de Gaula", en A. González y A. Campos García-Rojas (eds.) (2009): 55-93.

Cacho Blecua, J. M. y M. C. Marín Pina (2009): “La rivalidad caballeresca de Carlos V y Francisco I (Épica culta y carteles de desafío)", en M. Boixareu y R. Lefere (eds.) (2009): 195-214.

Carro Carbajal, E. B. et al. (eds.) (2002): Libros de caballerías (De "Amadís" al "Quijote"). Poética, lectura, representación e identidad, Salamanca, Seminario de Estudios Medievales y Renacentistas; Sociedad de Estudios Medievales y Renacentistas. Company, C. et al. (eds.) (2005): Textos medievales: recursos, pensamiento e influencia, México, Universidad Autónoma de México; Universidad Autónoma Metropolitana; El Colegio de México.

Contamine, P. (1984): La guerra en la Edad Media, Barcelona, Labor.

Cuesta Torre, María Luzdivina (1998): "Ética de la guerra en el Libro del caballero Zifar", en R. Beltrán (ed.) (1998): 95-114.

Cuesta Torre, María Luzdivina (1999a): “La guerra en el Amadís de Montalvo", J. E. Martínez (ed.) (1999): 113-132.

Cuesta Torre, María Luzdivina (1999b): “En torno al tema de la guerra en el Libro del caballero Zifar", en S. Fortuño Lloréns y T. Martínez Romero (eds.) (1999): 113124.

Cuesta Torre, María Luzdivina (2002): “El episodio del combate singular: de la novela artúrica francesa a los libros de caballerías españoles", en J. E. Martínez et al. (eds.) (2002): 519-530.

Florisando = Páez de Ribera (1510): Florisando, Salamanca, Juan de Porras.

Floriseo $=$ Fernando Bernal (2003), Floriseo, ed. J. Guijarro Ceballos, Alcalá de Henares, CEC, Col. Los Libros de Rocinante, 14.

Fortuño Lloréns, S. y T. Martínez Romero (eds.) (1999): Actes del VII Congrés de l'Associació Hispànica de Literatura Medieval (Castelló de la Plana, 22-26 de setembre de 1997), Castelló de la Plana, Publicacions de la Universitat Jaume I.

Garcia, M. (2001): “Chevalerie et politique en Castille: Histoire d'un défi et son arrièreplan politique (1413-1414)", en G. Martin (dir.) (2001): 81-99.

González, A. y A. Campos García Rojas (eds.) (2009): Amadís y sus libros: 500 años, México, D.F., El Colegio de México.

Lisuarte = Feliciano Silva (2002): Lisuarte de Grecia, ed. E. J. Sales Dasí, Alcalá de Henares, CEC, Col. Los Libros de Rocinante, 12.

Lucía Megías, J. M. (1996): “Dos caballeros en combate: batallas y lides singulares en La leyenda del caballero del Cisne y el Libro del caballero Zifar", en C. Alvar y J. M. Lucía (eds.) (1996): 427-452. 
Lucía Megías, J. M. y M. C. Marín Pina (eds.) (2008): Amadís de Gaula: quinientos años después. Estudios en homenaje a Juan Manuel Cacho Blecua, Alcalá de Henares, Centro de Estudios Cervantinos.

Madero, M. (1987): “El riepto y su relación con la injuria, la venganza y la ordalía (Castilla y León, siglos XIII y XIV)", Hispania. Revista Española de Historia, XLVII, 167: 805-861.

Madero, M. (1992): Manos violentas, palabras vedadas. La injuria en Castilla y León (siglos XIII-XV), Madrid, Taurus Humanidades, prol. Jacques Le Goff.

Marín Pina, M. ${ }^{a}$ C. (2005): “Las coplas del Primaleón y otros versos laudatorios en los libros de caballerías", en R. Alemany et al. (coords.) (2005): 1057-1066.

Martin, G. (dir.) (2001): La chevalerie en Castille à la fin du Moyen Âge. Aspects sociaux, idéologiques et imaginaires, Paris, Ellipses.

Martín Romero, J. J. (2006): “'Aquellos furibundos y terribles golpes': la expresión del combate singular en los textos caballerescos", Revista de Filología Española, 86, 2: 293-314.

Martínez, J. E. (ed.) (1999): Trilcedumbre. Homenaje a Francisco J. Martínez García, León, Universidad de León.

Martínez, J. E. et al. (eds.) (2002): Estudios de Literatura Comparada. Norte y Sur. La sátira. Transferencia y recepción de géneros y formas textuales. Actas del XIII Simposio de la Sociedad Española de Literatura General y Comparada, León, Universidad de León; Secretariado de Publicaciones.

Orejudo, A. (1993): Cartas de batalla, Barcelona, PPU.

Otero Varela, A. (1955): “El riepto en el derecho castellano-leonés”, en Dos estudios histórico-jurídicos, Roma-Madrid, CSIC, pp. 153-173.

Palmerín = Palmerín de Olivia (Salamanca, [Juan de Porras], 1511) (2004): ed. G. di Stefano, intr. M. ${ }^{a}$ C. Marín Pina, Alcalá de Henares, CEC, Col. Los Libros de Rocinante, 18.

Partidas = Alfonso X (1807): Las siete partidas del rey don Alfonso el Sabio, ed. facsímil, Madrid, Imprenta Real, 3 vol.

Penna, M. (ed.) (1959): Prosistas castellanos del siglo XV, Madrid, Atlas.

Pérez, J. (1995): “La hora de Cisneros”, en J. Pérez (coord.) (1995): 11-22.

Pérez, J. (coord.) (1995): La hora de Cisneros, Madrid, Universidad Complutense.

Pérez Cortés, S. (1996): “La ofensa, el mentís y el duelo de honor", Revista internacional de filosofía política, 8: 107-119.

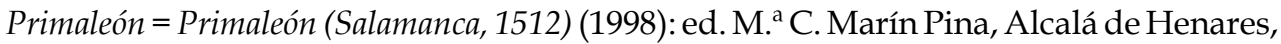
CEC, Col. Los Libros de Rocinante, 3.

Río Nogueras, A. (1989): “El Don Florindo de Fernando Basurto como tratado de rieptos y desafíos", Alazet, 1: 175-194. 
Riquer, M. y M. Vargas Llosa (1972): El combate imaginario: las cartas de batalla de Joanot Martorell, Barcelona, Breve Biblioteca de Respuesta.

Sergas de Esplandián = Garci Rodríguez de Montalvo (2003): Sergas de Esplandián, ed. C. Sainz de la Maza, Madrid, Clásicos Castalia.

Sesma, Á. (1978): “Carteles de batalla cruzados entre Alfonso V de Portugal y Fernando V de Castilla (1475)", Revista Portuguesa de Historia, XVI: 278-295.

Thompson, S. (1932-1937): Motif-Index of Folk-Literature. A classification of Narrative Elements, Helsingfors-Bloomington, FFC-Indiana University Studies, 6 vol.; ed. revisada, Copenhagen-Bloomington, 1955-1958.

Trujillo, D. (ed.) (1986): Estudios en homenaje al Dr. Antonio Beltrán Martínez, Zaragoza, Facultad de Filosofía y Letras; Universidad de Zaragoza.

Valera, D. (1959): “Tratado de armas”, en M. Penna (ed.) (1959): 118-139.

Ziegler, V. L. (2004): Trial by Fire and Battle in Medieval German Literature, USA, Camden House. 